\title{
TERAPIA PERIODONTAL DE SUPORTE OBJETIVOS, PROCEDIMENTOS E INTERVALOS
}

\author{
SUPPORTIVE PERIODONTAL THERAPY \\ OBJECTIVES, PROCEDURES AND VISITS
}

Fernanda Zander Grande ${ }^{1 *}$, Fabiana B. T. Alves ${ }^{1}$, Christiana Zander Grande ${ }^{2}$, Fábio André dos Santos ${ }^{3}$, Gibson Luis Pilatti ${ }^{3}$

1* Autor para contato: Universidade Estadual de Ponta Grossa - UEPG, Departamento de Odontologia, Campus em Uvaranas, Ponta Grossa, PR, Brasil; (42) 3225-5323; e-mail: fzgrande@yahoo.com.br

2 Universidade Estadual de Ponta Grossa - UEPG, Programa de Pós-graduação em Odontologia, Campus em Uvaranas, Ponta Grossa, PR

3 Universidade Estadual de Ponta Grossa - UEPG, Programa de Pós-graduação em Odontologia, Campus em Uvaranas, Ponta Grossa, PR

Recebido para publicação em 04/06/2007 Aceito para publicação em 24/08/2007

\section{RESUMO}

A terapia periodontal de suporte (TPS) é de grande importância para que o tratamento periodontal cirúrgico ou não-cirúrgico seja efetivo a longo prazo. O objetivo da TPS é manter os resultados da terapia periodontal ativa, restabelecendo a saúde do paciente, diminuindo a recorrência da doença periodontal e da mortalidade dentária. Nas reconsultas um novo exame é feito e os procedimentos necessários são executados, renova-se a motivação do paciente e sua responsabilidade em cooperar com o tratamento, comparecendo às consultas e fazendo um eficiente controle de placa. Os intervalos das reconsultas são adaptados de acordo com a necessidade de cada paciente. Pacientes que não receberam tal tratamento normalmente sofreram recorrência da doença periodontal. É função não só do periodontista como do clínico geral, desenvolver um plano de tratamento com freqüente terapia de manutenção. Serão discutidos neste artigo objetivos, procedimentos e intervalos da TPS.

Palavras-chave: doença periodontal, terapia periodontal de suporte, manutenção periodontal. 


\begin{abstract}
The periodontal supportive therapy is very important for a successful treatment. The purpose of this maintenance therapy is to restore the patient's health, decrease the recurrence of the periodontal disease and reduce the incidence of tooth loss. During maintenance a new examination and, if necessary, a new treatment, must be done. Thus, the patient's motivation and responsibility in cooperating with the treatment are renewed. The intervals are adapted to the patient's needs. Specialized periodontal clinics and general dental practitioners have to develop treatments with frequent maintenance therapies. This article presents the objectives, the procedures and the intervals between visits necessary for a good supportive periodontal therapy.
\end{abstract}

Key words: periodontal disease, periodontal supportive therapy, periodontal maintenance.

\section{Introdução}

O tratamento periodontal é constituído de uma fase ativa e de uma fase complementar. O tratamento periodontal ativo, objetiva a eliminação da doença periodontal, restabelecendo não só a saúde dos tecidos periodontais como de toda a cavidade bucal, porém apenas esta fase é insuficiente para o sucesso do tratamento, necessitando então de uma extensão que se encarregue da manutenção dos procedimentos executados anteriormente. A terapia de manutenção ou terapia de suporte periodontal (TPS), como preconiza a Academia Americana de Periodontia, é essa extensão da terapia periodontal ativa, que visa evitar a reincidência da doença.

A cárie e a doença periodontal são patologias que acometem a maior parte da população brasileira com altos níveis de prevalência e incidência. Portanto, existe a necessidade de um tratamento universal que atinja as duas patologias, de maneira que o periodontista e o clínico geral trabalhem em conjunto, sem apenas limitarem-se ao tratamento periodontal ou ao tratamento de processos cariosos, respectivamente.

Após o tratamento periodontal ativo, o paciente deve ser transferido para um programa de manutenção, sendo um passo definitivo nos cuidados gerais que requer tempo e esforço por parte do dentista e sua equipe. Os pacientes devem entender o propósito do programa de manutenção, enfatizando-se que a preservação do dente depende disso (MERIN, 1996).

Visitas periódicas formam uma estrutura significativa para um programa de prevenção prolongado. O intervalo mais comum entre as visitas é inicialmente de três meses, mas pode variar de acordo com as necessidades de cada paciente. A preservação a longo prazo da dentição está altamente relacionada com a freqüência e qualidade da fase de manutenção (MERIN, 1996).

Um tratamento periodontal onde a terapia de manutenção não foi cumprida pode resultar em recorrência da progressão da doença, com essas informações os pacientes serão capazes de decidir a respeito de sua terapia periodontal (ACADEMIAAMERICANADE PERIODONTIA, 2000).

Serão discutidos a importância e os objetivos da terapia periodontal de suporte, instituindo critérios de retorno e atividades clínicas praticadas no mesmo, orientando não apenas o periodontista como também o clínico geral, como proceder durante a manutenção do tratamento periodontal, demonstrando seus respectivos papéis nesta situação.

\section{Revisão de literatura}

Para Merin (1996), pacientes que não participaram de um programa de manutenção periodontal, após a terapia ativa, usualmente mostraram sinais de 
periodontite recorrente, apresentando sinais como: aumento da profundidade das bolsas, perda óssea e até perda dentária. Porém, não existe razão para simplesmente informarmos ao paciente que ele deverá retornar para as consultas periódicas sem explicar o motivo das visitas e sem propor o que se espera dele entre uma consulta e outra. As reconsultas são semelhantes ao exame inicial do paciente, são feitas atualização na história médica e avaliação das restaurações, placa e cálculo, cáries, próteses, oclusão, mobilidade dentária, estado gengival e bolsas periodontais. As radiografias são de extrema importância para comparações com radiografias prévias checando a altura óssea, reparos de defeitos ósseos, sinais de traumas oclusais, mudanças periapicais e cáries. Após a verificação destes itens, podem ser necessários nova raspagem e alisamento radiculares seguidos de uma profilaxia, complementados com a utilização de agentes antimicrobianos. Se a doença for recorrente nova raspagem deve ser realizada. Perante novo insucesso cirurgias só devem ser realizadas se o paciente tiver demonstrado cooperação executando adequadamente sua parte da terapia.

Lang et al. (1997) afirmaram que o objetivo de uma cuidadosa manutenção seria a preservação contínua da saúde gengival e periodontal, obtida como resultado de um tratamento periodontal ativo. A preservação periodontal seria conseguida pela remoção regular da microbiota subgengival, suplementada por um excelente controle de placa executado pelo paciente. Os autores dividiram suas sessões de rechamadas em quatro partes: os primeiros 10-15 minutos são reservados para o exame, reavaliação e diagnóstico; a segunda parte consome a maior parte do tempo, de 30-40 minutos, é dedicada para reinstrução e instrumentação dos sítios de risco identificados no diagnóstico. Certos sítios reinfectados podem requerer um tratamento mais demorado e o paciente pode ser programado para uma consulta adicional. A sessão de rechamada é concluída com o polimento dos dentes, aplicação de flúor e determinação da freqüência da futura visita de terapia periodontal de suporte. Os pesquisadores verificaram também que estudos longitudinais sobre o sucesso nos tratamentos periodontais destacam o papel decisivo da terapia periodontal de suporte na manutenção dos resultados conseguidos na terapia periodontal ativa. Nesses estudos a profundidade de sondagem, os níveis de inserção clínica foram mantidos

Lindhe e Nyman (1997) observaram que os intervalos de tempo entre as reconsultas no tratamento de manutenção periodontal devem estar sempre relacionados com a capacidade do paciente de manter um padrão adequado de higiene bucal. Assim a revisão deve ser planejada para satisfazer as necessidades individuais do paciente. Certos pacientes mais propensos à doença devem ser revisados todos os meses, enquanto outros podem ser examinados anualmente.

Nyman e cols. (1975) apud Lang (1997), em seu experimento, observaram que pacientes com periodontite avançada tratados com técnicas cirúrgicas, mas não incorporados a um programa de manutenção, mostraram periodontite recorrente com uma perda de inserção bem acima do que a reportada na progressão natural da doença em populações sensíveis a doença.

Segundo Tunes e Rapp (1999), no Brasil preferiu-se conservar o termo Manutenção, por conferir maior ênfase, sendo uma tradução mais adequada. A manutenção se faz necessária, pois os fatores causais da doença periodontal não apresentam cura definitiva. Então essa fase objetiva: assegurar a estabilidade dos resultados, minimizar a recorrência da doença periodontal, avaliar a resposta dos tecidos periodontais ao tratamento periodontal ativo, reforçar hábitos de higiene bucal pessoal e prevenir ou reduzir a incidência de perda dentária. Os autores afirmaram ainda que não existe uma concordância entre os intervalos das reconsultas e que estes variam de acordo com cada autor, portanto cientificamente não existiriam evidências absolutas para se recomendar indiscriminadamente para todos pacientes intervalos de $3 / 3$ meses ou ainda de 6/6 meses e sim adaptar as rechamadas de acordo com a necessidade e o risco de cada paciente.

AAcademia Americana de Periodontia (2000) enfatizou que os objetivos da TPS são: minimizar a recorrência e a progressão da doença periodontal em pacientes que tenham sido tratados previamente de periodontite e gengivite; reduzir a incidência de mortalidade dentária por meio do monitoramento da dentição e substituição protética dos dentes naturais; aumentar a probabilidade de localizar e tratar, periodicamente, outras doenças e condições encontradas 
na cavidade bucal. As etapas da TPS delineadas pela AAP são:

- Revisão e atualização da história médica e dentária

- Exame clinico (a ser comparado com medições básicas prévias)

1. Exame extra-bucal e registro dos resultados.

2. Exame dentário e registro dos resultados:

a. Mobilidade dentária/ frêmito;

b. Avaliação de cáries;

c. Restaurações, próteses;

d. Outros problemas relacionados ao dente.

3. Exame periodontal e registro dos resultados:

a. Profundidade de sondagem;

b. Sangramento sob sondagem;

c. Níveis gerais de placa e cálculo;

d. Avaliação de invasão de furca;

e. Exsudação;

f. Recessão gengival;

g. Exame oclusal e mobilidade dentária;

h. Outros sinais e sintomas de atividade de doença.

4. Exame de implantes dentais e tecidos periimplantares com registro dos resultados:

a. Profundidade de sondagem;

b. Sangramento sob sondagem;

c. Exame dos componentes da prótese e abutments;

d. Avaliação da estabilidade do implante;

e. Exame oclusal;

f. Outros sinais e sintomas de atividade de doença.

- Exame radiográfico:

As radiografias devem ser atuais e baseadas nas necessidades diagnósticas do paciente, devendo permitir avaliação apropriada e interpretação do estado do periodonto e implantes dentários. Radiografias de qualidade diagnóstica são necessárias para estes propósitos. O julgamento do clínico, tanto quanto o grau de atividade da doença, podem auxiliar a determinar a necessidade e a freqüência do numero de radiografias. Anormalidades radiográficas devem ser notadas.

- Avaliação

1. a avaliação do estado da doença deve ser revisada com os achados dos exames clínicos e radiográficos comparados com o exame básico.
2. Avaliação do estado de higiene bucal pessoal.

- Tratamento cálculo;

1. remoção da placa sub ou supragengival e

2. Modificação do comportamento:

a. Reinstrução de higiene bucal;

b. Cooperação com os intervalos de manutenção periodontal sugeridos;

c. Aconselhamento sob o controle dos fatores de risco, por exemplo, cessar com o hábito de fumar.

3. Agentes antimicrobianos quando necessário;

4. Tratamento cirúrgico da recorrência da doença.

- Comunicação

1. Informar o paciente co estado atual e alterações no tratamento, se indicado;

2. Consulta com outros profissionais de saúde que irão proporcionar uma terapia adicional ou participação no programa de manutenção periodontal.

- Planejamento

1. Para a maioria dos pacientes com uma história de periodontite, as visitas de intervalos de 3 meses tem sido efetivas em manter a estabilidade da saúde gengival;

Baseado na avaliação dos achados clínicos e do estado da doença, a freqüência de manutenção periodontal pode ser modificada ou o paciente pode ser retornado ao tratamento ativo.

Jovino Silveira et al. (2001) verificaram que a terapia de suporte periodontal deveria ser incorporada como parte integrante da prática periodontal. Nessa fase tipicamente são realizadas, instrução de higiene oral, avaliação da profundidade de sondagem, revisão do controle de placa, verificação de defeitos ósseos na profundidade de sondagem, índice de sangramento, mobilidade dentária, raspagem radicular, remoção de placa subgengival em bolsas de $4 \mathrm{~mm}$ e envolvimento de furca e por fim profilaxia supragengival. $\mathrm{O}$ autor verificou que os intervalos para tal manutenção variam muito de acordo com cada pesquisador, mas comumente são estabelecidos como trimestrais e quadrimestrais, embora devam ser estabelecidos de acordo com a necessidade de cada paciente, pois pacientes mais susceptíveis a doença necessitam de intervalos menores e pacientes resistentes podem ter seus intervalos aumentados. Observou grande dificuldade em conseguir a cooperação do paciente, no compareci- 
mento as reconsultas. Encontrou como motivos principais dessa falta de cooperação dos pacientes: considerar o tratamento caro, desnecessário e longo. Assim delegou ao periodontista motivar o paciente para que ele entenda e colabore nessa etapa essencial ao sucesso do tratamento.

O determinante clínico de maior importância na terapia periodontal não seria a técnica (cirúrgica ou não cirúrgica) utilizada na eliminação da infecção subgengival, mas sim a qualidade do programa de motivação, de manutenção e de controle. (PADOVANI e SHABA CHUJFI, 1991).

No Tratamento Periodontal de Suporte os intervalos para as rechamadas variam de acordo com cada autor, existindo uma variação de 2 semanas até 18 meses de intervalo, assim existe um tendência a individualizar os intervalos das rechamadas de acordo com a necessidade real de cada paciente. Pacientes que cooperaram e receberam a manutenção com maior freqüência tiveram um decréscimo na progressão de suas doenças e perderam menos dentes em relação aos pacientes menos freqüentes a terapia (ACADEMIA MERICANA DE PERIODONTIA, 2003).

Lorentz et al. (2004) desenvolveram um projeto de extensão “Terapia Periodontal de Suporte” com base em reconsultas periódicas trimestrais, com o objetivo de minimizar a recorrência e a progressão da doença periodontal em pacientes que tenham sido tratados previamente, reduzir a perda dentária, restabelecer a saúde periodontal e melhorar a higiene bucal. Os autores observaram que os pacientes com doença periodontal tinham grande dificuldade em controlar o acúmulo de placa e cálculo sobre os elementos dentais e conseqüentemente, evitar suas ações sobre os tecidos periodontais. Durante a manutenção os pacientes passaram por um novo exame completo, onde foram analisados índices como profundidade de sondagem, sangramento sob sondagem, avaliação de invasão de furca, recessão gengival, exame oclusal e mobilidade dentária, níveis de placa e cálculo entre outros sinais e sintomas de doença. Após análise foram feitos raspagem supragengival, raspagem e alisamento radicular sob anestesia por sextante, profilaxia, aplicação de flúor, escovação orientada e instruções de higiene, bucal e radiografias periapicais e interproximais em áreas com bolsas maiores que $5 \mathrm{~mm}$, portanto o paciente além de um novo exame e tratamento tem sua motivação renovada.

Para Rego e Silva (2004), o conceito biológico de saúde esta relacionado à anfibiose e homeostase, à qualidade e quantidade dos agentes bacterianos agressores e seu equilíbrio maior ou menor com o hospedeiro. Assim a manutenção é atingida com o tratamento periodontal ativo associado à regularidade e competência dos cuidados próprios domiciliares e visitas periódicas ao profissional. Pórem estas reconsultas devem ser feitas com critérios, pois consultas periódicas baseadas em um modelo burocrático e tecnicista, sem princípios e procedimentos fundamentados em um real controle e eliminação de doenças periodontais e cáries, têm sido ineficazes, mesmo que sejam realizados com freqüência rigorosa. O critério mais utilizado para estipular a peridiocidade das reconsultas é chamado riso do paciente, os pacientes que possuem maior risco a doença periodontal normalmente necessitam de um intervalo menor pra as rechamadas e os pacientes menos sensíveis de intervalos maiores. Esse risco pode estar relacionado a: acúmulo de placa bacteriana, acúmulo de cálculo, higiene deficiente, dieta e nutrição, tabagismo, ansiedade, anomalias de forma e posição dentária, trabalhos protéticos e tratamento ortodôntico, má oclusão e oclusão traumatogênica, hábitos viciosos (onicofagia, respiração bucal, deglutição atípica), bruxismo, aspectos genéticos e hormonais, medicamentos diversos e idade. A manutenção visa assegurar a estabilidade dos dentes, minimizar recidivas, reforçar hábitos de higiene bucal pessoal, prevenir e reduzir a mortalidade dentária.

Renvert e Persson (2004) sustentaram não existir um tratamento que cure a doença periodontal, assim faz-se necessário um acompanhamento por meio da terapia periodontal de suporte. Os objetivos do tratamento que são manter funcionalmente e esteticamente a dentição, são alcançado com o conjunto profissional e performance do paciente no controle de placa. A doença recorre nos grupos chamados de alto riso ou de extremo comprometimento imune. Os intervalos das rechamadas são variáveis e baseados em diversos experimentos, mas o padrão adotado é de 3-4 meses de intervalo.

Segundo Wilson et al. (1993) apud Lorentz et al. (2004), pacientes que freqüentemente recebem terapia periodontal de suporte tendem a manter seus 
dentes por um período mais longo e desfrutam de maior saúde periodontal do que pacientes que não recebem tal tratamento, ou seja, quanto mais espaçado o intervalo de manutenção periódico, maior a mortalidade dentária.

Preshaw e Heasman (2005) verificaram em seu estudo que a terapia periodontal de suporte periodontal não cirúrgico pode ser feita tanto pelo periodontista quanto pelo clínico geral, desde que o clínico geral tenha instruções específicas e detalhadas de como desenvolver e realizar um plano de manutenção periodontal.

\section{Discussão}

A Terapia de Manutenção Periodontal, também chamada de Terapia Periodontal de Suporte, é uma extensão do tratamento periodontal ativo. Ela se faz necessária, pois os fatores causais da doença periodontal não apresentam cura definitiva. (TUNNE e RAPP, 1999; RENVERT e PERSSON, 2004). Essa terapia só é eficaz com a cooperação do paciente em controlar a sua placa bacteriana associada às visitas periódicas ao profissional (LANG et al., 1997; REGO e SILVA, 2004; RENVERT e PERSON, 2004).

Os objetivos principais da terapia de suporte periodontal são, manter os resultados da terapia ativa, minimizar a recidiva da doença periodontal, reforçar hábitos de higiene bucal pessoal e prevenir e reduzir a mortalidade dentária. (TUNES e RAPP, 1999; AAP, 2000; LORENTZ et al., 2004; REGO e SILVA, 2004) Ou ainda manter funcionalmente e estéticamente a dentição (RENVERT e PERSSON, 2004), tratar outras doenças e condições encontradas na cavidade bucal (AAP, 2000) e preservar a saúde gengival e periodontal conseguidas com o tratamento periodontal ativo (LANG et al., 1997).

Nas reconsultas os pacientes passam por um novo exame semelhante ao inicial (MERIN, 1996; LORENTZ et al., 2004). Normalmente é feita uma revisão da história médica e um exame clínico para comparar com os índices medidos anteriormente(AAP, 2000). São checados itens como, cáries, próteses, oclusão, mobilidade dentária, estado gengival e periodontal geral (sangramento, recessão, bolsas, invasão de furca), níveis de placa e cálculo e outros sinais e sintomas de doença. (MERIN, 1996, AAP. 2000; JOVINO SILVEIRA et al., 2001; LORENTZ et al., 2004). As radiografias são de grande importância na análise de alguns parâmetros como altura e defeitos ósseos. (MERIN, 1996; AAP, 2000)

Após reexame normalmente são executados procedimentos para renovar a motivação do paciente. Se necessária uma nova raspagem é feita, seguida de flúor e profilaxia, sempre acompanhados de reinstrução de higiene bucal (MERIN, 1996; LANG, 1997; AAP, 2003; LORENTZ et al., 2004). Podem ser utilizados ainda agentes antimicrobianos para complementar o tratamento (MERIN, 1996; AAP, 2003). Nessa fase deve-se determinar a futura reconsulta. (LANG et al.,1997). Se a doença periodontal recorrer, nova raspagem deve ser tentada. Procedimentos cirúrgicos somente são adotados quando a doença recorre em pacientes que cumpriram sua parte adequadamente na terapia. (MERIN, 1996).

Segundo a literatura os intervalos para reconsultas ou rechamadas do tratamento de suporte variam muito de acordo com cada autor e suas pesquisas (TUNES e RAPP, 1999; JOVINO SILVEIRA et al., 2001; AAP, 2003; RENVERT e PERSSON, 2004), essa variação pode ser de 2 semanas a 18 meses (AAP, 2003), mas o padrão classicamente adotado é de visitas trimestrais ou quadrimestrais (AAP, 2000; JOVINO SILVEIRA et al., 2001; RENVERT e PERSSON, 2004)

No entanto existe um consenso de que os intervalos devem ser determinados por um critério chamado risco do paciente (REGO e SILVA, 2004), ou seja, os intervalos seriam adaptados de acordo com as necessidades de cada paciente (LINDHE e NYMAN, 1997; TUNES e RAPP, 1999; JOVINO SILVEIRA et al., 2001; AAP 2003), e sua capacidade de manter o padrão adequado de higiene bucal (LINDHE e NYMAN, 1997). Assim pacientes com grande risco de doença periodontal necessitam de intrevalos menores para reconsultas enquanto pacientes menos sensíveis a doença podem ter seus intervalos estendidos. (LINDHE e NYMAN, 1997; JOVINO SILVEIRA et al., 2001; REGO e SILVA, 2004).

Os riscos atribuídos aos pacientes são: higiene deficiente, acúmulo de placa e cálculo, dieta e nutrição, tabagismo, ansiedade, anomalias de forma e posição 
dentária, próteses, tratamento ortodôntico, má oclusão, hábitos viciosos, disfunções e parafunções, aspectos hormonais, genética, medicamentos e a própria idade (REGO e SILVA, 2004).

Pacientes que receberam a manutenção mais freqüentemente desfrutaram de um decréscimo na evolução de suas doenças conseqüentemente maior saúde periodontal e menor taxa de mortalidade dentária em relação aos pacientes que não receberam tal tratamento. (AAP, 2003; WILSON et al., 1993 apud LORENTZ et al., 2004)

Os pacientes que não participaram de um tratamento de manutenção após a terapia periodontal ativa, normalmente mostraram sinais de periodontite recorrente (MERIN, 1996), em alguns casos com perdas periodontais maiores do que a progressão natural da doença (NYMAN et al., 1975 apud LANG, 1997).

Para que a manutenção obtenha o sucesso desejado, as reconsultas devem ser feitas com critérios e fundamentos, e o paciente deve estar ciente do seu papel e do que o dentista espera dele (MERIN 1996; REGO e SILVA, 2004).

Os pacientes não colaboram com a terapia de manutenção, usualmente acham o tratamento desnecessário, longo e caro (JOVINO SILVEIRA, 2001). Portanto é necessário esclarecer ao paciente os motivos do tratamento e as conseqüências da ausência do mesmo.

Poucos autores relataram o papel do clínico geral na terapia de manutenção periodontal. O clínico geral se bem orientado e instruído pode realizar o tratamento periodontal de manutenção não cirúrgico tanto quanto o periodontista (PRESHAW e HEASMAN, 2005).

\section{Conclusões}

A terapia periodontal de suporte é tão importante quanto o tratamento periodontal ativo e um correto diagnóstico. O tratamento periodontal bem sucedido depende de um adequado controle, executados em conjunto pelo profissional e paciente. Os objetivos principais da manutenção são prevenir e minimizar a progressão e recorrência da doença, restabelecer a saúde, reduzir a mortalidade dentária e identificar e tratar precocemente possíveis sinais de outras doenças na cavidade bucal. Apenas o cuidado domiciliar do paciente não é suficiente, assim após o tratamento ativo, independentemente da técnica terapêutica utilizada, um rigoroso plano de visitas periódicas deve ser instituído individualmente de acordo com a necessidade e risco de cada paciente. Este paciente se tornará parceiro do profissional, compreendendo a importância de seu papel para o tratamento. Os pacientes não submetidos, ou não cooperadores, ao tratamento de manutenção normalmente sofrem recorrência da doença. Tanto o periodontista quanto o clínico devem desenvolver um plano de tratamento com freqüente e eficaz terapia de manutenção

\section{REFERÊNCIAS}

1AMERICANACADEMY OF PERIODONTOLOGY. Parameter of care. J Periodontol, Chicago, v. 71 (supplement), n. 5, p. 849-850, May 2000.

2 AMERICAN ACADEMY OF PERIODONTOLOGY. Periodontal Maintenance. J Periodontol. ; v. 74, p. 1395-1401, 2003.

3 JOVINO SILVEIRA, R. C.; LUZ, C. R. M.M.; SOUZA, E. H. A. et al. Terapia periodontal de suporte. Rev. Cons. Reg. Odontol. Pernambuco, v. 4, n. 1, p. 07-11, Jan/Jun 2001.

4 LANG, N. P. et al. Terapia peridontal de suporte (TPS). In: LINDHE, J. Tratado de periodontia clínica e implantologia oral. 3. ed. Rio de Janeiro: Guanabara Koogan, 1997.

5 LINDHE, J.; NYMAN, S, Plano de tratamento. In: LINDHE, J. Tratado de periodontia clínica e implantologia oral. 3. ed. Rio de Janeiro: Guanabara Koogan, 1997.

6 LORENTZ, T. C. M.; COSTA, F. O.; MOREIRA, A. N. et al. Monitoramento da saúde periodontal dos pacientes tratados no projeto terapia periodontal de suporte. Anais do 7 Encontro de Extensão da UFMG, Belo Horizonte, Set: 2004.

7 MERIN, R. L. Tratamento periodontal. de suporte In: CARRANZA, F. A.; NEWMAN,M. G. Periodontia Clínica. 8. ed. Rio de Janeiro: Guanabra Koogan, 1996.

8 NYMAN, S.; ROSLING, B.; LINDHE, J. Effect of professional tooth cleaning on healing after periodontal surgery. $\mathbf{J}$. Periodontal Res. p. 80-86, 1975. apud LANG, N. P. et al. Terapia peridontal de suporte (TPS). In: LINDHE, J. Tratado de periodontia clínica e implantologia oral. 3. ed. Rio de Janeiro: Guanabara Koogan, 1997.

9 PADOVANI, M. C.; SABA-CHUJFI, E. Manutenção e controle no tratamento periodontal. APCD, São Paulo, v. 45, n. 2, p. 429-432, mar/abr 1991. 
10 PRESHAW, P. M.; HEASMAN, P. A. Periodontal maintenance in a specialist periodontal clinic and in general dental practice. J. Clin Periodontol. v. 32, p. 280-286, 2005.

11 REGO, N. G. C.; SILVA, D. F. Terapia Periodontal de Suporte: fundamentos, práxis e dinâmica. 2004 Abr [capturado em 2005 Fev 02]. Disponível em: http://www._Odontologia.com.br/ arigos.asp?id=460.

12 RENVERT, S.; PERSSON, R. Suportive periodontal therapy. Periodontology 2000. v. 36, p. 179-195, 2004.

13 TUNES, U. R.; RAPP, G. E. Atualização em periodontia e implantodontia. São Paulo: Artes Médicas, 1999, 375p.

14 WILSON JR, T. G.; HALE, S.; TEMPLE, R. The results of efforts to improve compliance with supportive periodontal treatment in a private practice. J. Periodontol. v. 64, n. 4, p. 311-314, 1993 apud LORENTZ, T. C. M.; COSTA, F. O.; MOREIRA, A. N. et al. Monitoramento da saúde periodontal dos pacientes tratados no projeto terapia periodontal de suporte. Anais do 7 Encontro de Extensão da FO-UFMG, Belo Horizonte, Set: 2004. 